\title{
Strengthening the delivery of comprehensive reproductive health services at the community level in Kenya
}

Population Council

Follow this and additional works at: https://knowledgecommons.popcouncil.org/departments_sbsr-rh

Part of the Demography, Population, and Ecology Commons, Family, Life Course, and Society

Commons, International Public Health Commons, Maternal and Child Health Commons, Medicine and Health Commons, and the Public Health Education and Promotion Commons How does access to this work benefit you? Let us know!

\section{Recommended Citation}

"Strengthening the delivery of comprehensive reproductive health services at the community level in Kenya," APHIA II Operations Research Project in Kenya OR Summary. Nairobi: Population Council, 2011. 


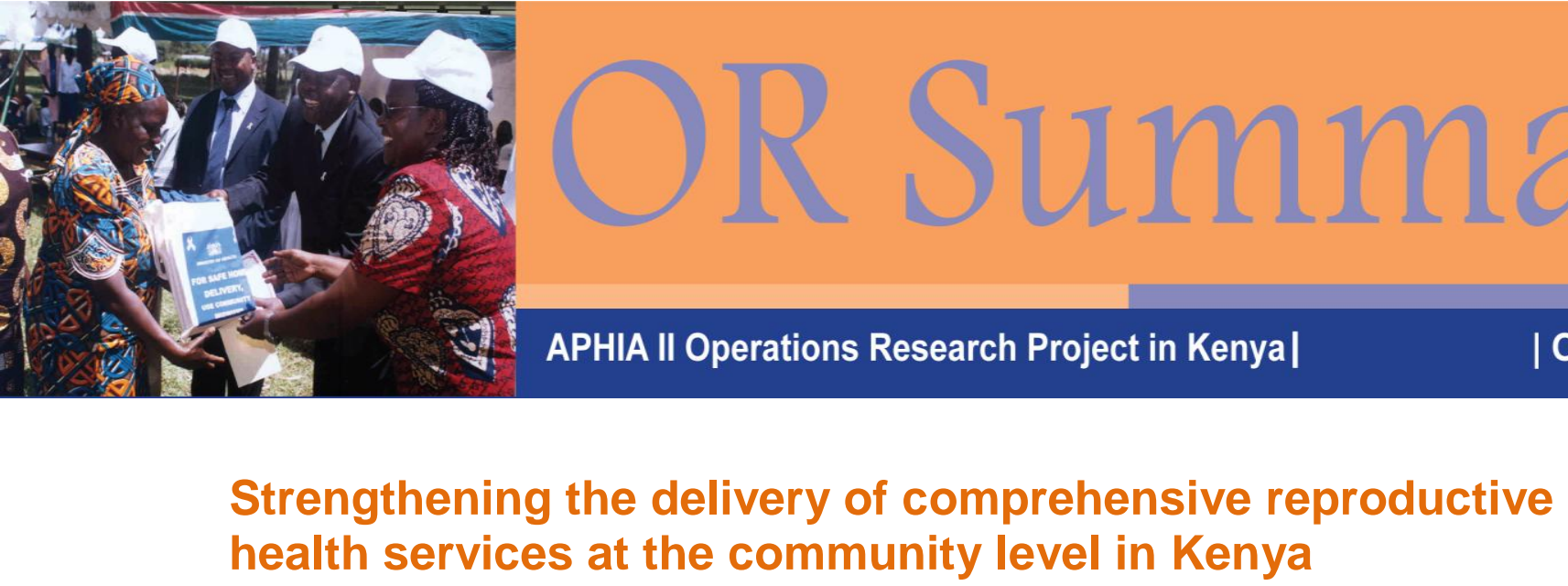

\section{Strengthening the delivery of comprehensive reproductive health services at the community level in Kenya}

\section{Background}

In Kenya, maternal deaths comprise about $15 \%$ of all deaths to women aged $15-49$ years, while neonatal mortality is 31 deaths per 1,000 live births. In addition, more than half of all pregnant women [56.2\%] deliver at home under unskilled attendance, and utilization of antenatal and post-natal care is inadequate. To address these challenges, the Ministry of Health and partners developed the 'community midwifery' model in 2005, where retired midwives in the community were trained to provide basic services around pregnancy and birth. In 2011, APHIA II OR Project collaborated with the Ministry of Public Health and Sanitation to improve the quality of services offered by the community-based midwives in two districts in Western Kenya, to prepare them to offer more comprehensive maternal services through antenatal, obstetric, post-partum, and new-born care.

\section{The intervention}

Thirty-eight community midwives received 10-day training, which included provision of the long-acting family planning methods especially implant and IUCD; focused ante-natal care; prevention of mother-to-child transmission of HIV; delivery and post-partum care; and on how to provide a continuum of care. The training used the national safe motherhood guidelines, which were first revised to include an expanded maternal and child health services role for community midwives. All 38 midwives received training on the referral process and how to use referral cards for cases that they could not manage at community level. They also received updates in business management and entrepreneurship. Each also received a range of supplies and basic equipment essential to the provision of the services they had been trained on.

\section{Key findings}

- More women under care of community midwives initiated ante-natal care early: In general, majority of the women who delivered under the care of community midwives begin antenatal care early. Of the 313 pregnant women at endline who sought antenatal care from a community midwife, the majority $(80 \%)$ had made their first visit by 24 weeks (6months) and below. Only $22 \%$ had made the first visit after 25 weeks at endline.

- More women made at least four ANC visits: The proportion of pregnant women who made four visits to the community midwife for antenatal care increased from $27 \%$ at baseline to $34 \%$ at endline. A further $41 \%$ made $1-3$ visits, an increase from $37 \%$ at baseline. There was a reduction in those making more than five visits, from $34 \%$ at baseline to $26 \%$ at endline. 
- More deliveries managed by community midwives: More women in the study had delivered with the help of a community midwife than health facility staff, or a traditional birth attendant. Sixty per cent of women delivered under the care of a community midwife at her home at endline, an increase from $54 \%$ at baseline. Ninety-three per cent of clients who experienced complications while in labour or during delivery were managed by the community midwife at endline, and only $7 \%$ were referred, compared to $78 \%$ and $22 \%$ at baseline respectively.

- Majority of clients received prompt post-partum care: Overall, the proportion of new mothers under care of a community midwife, who received their first post-partum check-up within 48 hours after birth increased from $69 \%$ at baseline to $80 \%$ at endline.

- Uptake of LAPMs increased: The 38 community midwives jointly combined to an increase in the uptake of the IUCD and implants in the six month intervention period, as illustrated in Figure 1.

- Community midwives provide affordable services: A Cost analysis show that a community midwife's maternal health services are affordable, ranging from Kshs. 491 (US\$6) for the

Figure 1: Comparison of community midwives' FP methods workload during pre-and post intervention period

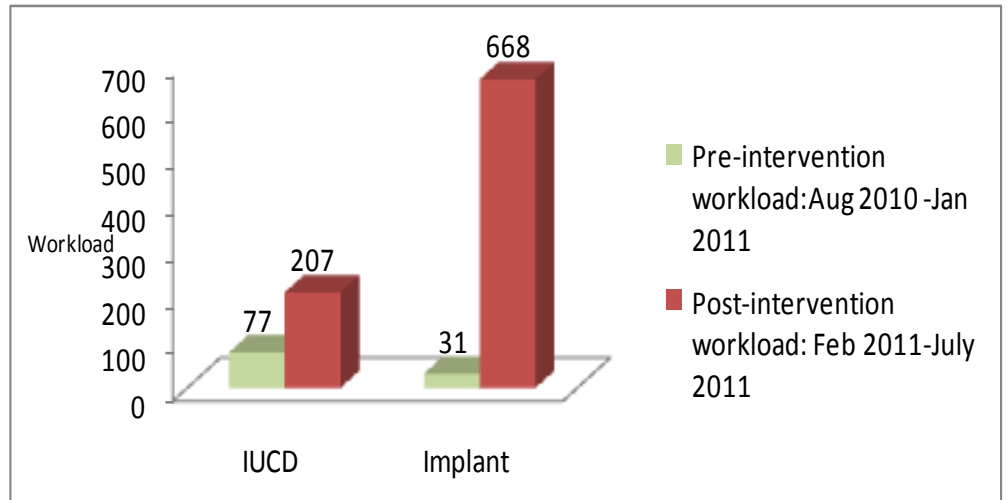

first ante-natal care visit to Kshs. 2,208 (US \$ 24) for labour management and delivery. Clients seeking their services were willing to pay more and to receive more reproductive health services from the midwives.

\section{Recommendations}

- Community midwives can tremendously increase clients' access to essential maternal health services and other reproductive health services. The Ministry of Health and its partners should scale up community midwives' activities to enable more women access these services.

- Information campaigns are needed to promote the range of services offered by community midwives.

- More focused training materials and curriculums for community midwives are needed, to enable them to offer a broader range of reproductive health services.

Source: Liambila W., H Birungi et al. 2011. Strengthening the Delivery of Comprehensive Reproductive Health Services at the Community Level in Kenya. APHIA II OR Project Report. Population Council, Nairobi

\section{(2) Population Council}

